Canadian Journal of Family and Youth, 13(3), 2021, pp. 99-108

ISSN 1718-9748@ University of Alberta

http://ejournals,library,ualberta.ca/index/php/cjfy

\title{
Who Falls in Love First? The Role Gender Plays in Love Expression
}

\author{
Abigail Odegard ${ }^{1}$
}

\begin{abstract}
Love is a universal feeling. It is present in every language and every culture. There is variability that exists between cultures, but the essence of love is the same. It is influential, it is impactful, it is a feeling that is sought after and being in love is considered one of the greatest successes. The expression of love has the ability to vary greatly. The extent of how love is expressed and how often or how much love is expressed varies from culture to culture. But the question of whether or not it varies between genders is still a point of interest to researchers. The timeline of people falling in love is a topic of discussion and who in a relationship will say the three magical words first is something to examine. Asking the question of who falls and says "I love you" first, men or women, will help explore romantic relationships.
\end{abstract}

${ }^{1}$ MacEwan University 


\section{Introduction}

The word 'love' is one that is heard in all cultures and can be considered a universal fact. The word 'love' and the feelings that surround it have the ability to travel across all boundaries and barriers; it is a universal concept that has a place in all societies. Falling in love can look different depending on what culture it is occurring in, but the impact of it can be considered as unanimously influential. The 'I love you' stage of intimate relationships is a milestone, one that is remembered and signifies a new level in a relationship. A question that arises is that "who tends to say it first" and whether or not this is a general rule that can be said about all couples and relationships or is it unique to each partnership.

It could be said that on average the majority of people would assume that the woman or female participant in a relationship feels these feelings first and often says it first. This assumption is reinforced by the countless romantic comedies that exist in Hollywood and the general thought that women fall hard and fast in relationships. If a person were to ask any random person on the street or in their lives who they believe falls in love first, men or women, the answer would predominantly be women. The concept of love is widely considered a soft subject, one that involves copious amounts of feelings and feminine energy. The narrative that surrounds 'love' and 'I love you' is full of stereotypes and the belief that women are considered more emotional and in tune with their feelings. Stereotypes do not only exist for women but for men as well. As women are seen as emotional and romantic, men are often seen as emotionally unavailable, cold, and not in tune with their feelings.

Despite the ongoing misconceptions that are circulating society, the traditional gender roles that society places on falling and being in love are not what actually occurs. This paper will discuss the research that exists around falling in love and the way that different genders express it. It will aim to disprove the stereotypes that prevail around the ideas of who says, "I love you" first and the way in which people express themselves while falling and being in love. This paper is attempting to prove that men on average fall in love faster and say "I love you' sooner in a relationship than women, and that the reasons for this lie within societies' socialization practices for men and women and traditional gender roles that are a byproduct of that. As well, this paper will provide evidence that human evolution and humans genes are also a contributing factor to the way, and to the timeframe, that different genders express their feelings of love.

\section{Literature Review}

Out of all the human emotions, love is one of the ones that people seek out. People spend their whole lives trying to find that one person who will enable them to feel all the symptoms of being in love. Love can be confusing, it can be rewarding, it is something that can overcome people's doubts, and it can help people conquer their fears. Love is a complex emotion that is felt universally but it expressed by cultures in many different ways.

The role of sex and gender in reference to love and the expression of love has been researched, but the stereotypes still persist (Harrison \& Shortall, 2011, p. 733), specifically regarding the timeline on the expression of love. According to Harrison and Shortall (2011), men are predominantly the ones who say it first in a relationship. This is not a recent phenomenon as 
earlier research has also shown that men say "I love you" first. In other words, this phenomenon has been around for decades (Harrison \& Shorthall, 2011, p. 728).

The question that is asked throughout the literature on this concept is, why do the stereotypes that exist around men and women falling in love and saying "I love you" first, still persist even though research has stated otherwise (Rubin, Peplau \& Hill, 1981, p. 822)? The idea that women are more romantic than their male counterparts is the ongoing stereotype, despite the data that is present that says that men, both older men and adolescent men, have a larger number of romantic tenencies than women do (Harrison \& Shorthall, 2011, p. 729).

In Harrison and Shorthall's (2011) study, they compare the research on 'love' and the way that men and women approach falling in love from a generation ago, to their current study that looks at participants' experiences with falling in and expressing love (p. 729). The hope of their research is to change the dialogue that has and currently exists with the notion that women are 'hopeless romantics', who fall in love quickly and on a whim, to the fact that women are particular and thoughtful when considering a relationship and being in one (Harrison \& Shorthall, 2011, p. 729). The research done on this topic is also hoping to dispel the stereotypes that exist around men as well, that they are romantic and they do have the capacity to fall in love first (Rubin et al., 1981, p. 822).

Stereotypes that exist around men and women falling in love reinforce the traditional gender roles that exist. By doing research that helps contradict and dispute the traditional claims, these researchers are demonstrating that love is not a gendered concept, rather, it is a feeling felt universally and that gender roles have no place in it. Although people of different genders do experience and show love differently, the typical stereotypes are often wrong, and it is important to recognize that when considering who falls in love first and who says "I love you" first.

\section{Stereotypes of Men and Women Falling and Being in Love}

Society is bombarded with ideas about love. There are whole industries that influence people's perceptions about love and romance. There are holidays focused around romantic love and there are whole genres in film and television that revolve around the process of falling and being in love. People's concept of falling and being in love is shaped and influenced by so many outside forces and this directly impacts people's perception on what love is, who feels it first, how it should be felt, and how it should be expressed.

Society is primed to believe that that women are more emotional and more readily willing to verbally express their feelings of love. Society is also primed to believe that men lack emotional fortitude to express their feelings first to their partner. These ideas are reinforced by the television and films people watch and industries that market romance.

This is an area of inquiry which has perhaps been explored most thoroughly by songwriters, comic book creators, and other producers of popular culture both today and in times gone by. It is an area in which stereotypes reign supreme. If our reading of the popular wisdom is correct, the most common set of perceptions holds that of the two sexes, women are the more starry-eyed and sentimental, while men are the more hardhearted and rational (Rubin et al. 1981, p. 822). 
Gender stereotypes are deep rooted in society, they exist in all facets and they influence so many areas of thought. Through the research and literature surrounding saying "I love you" and the gender differences that exist alongside it, the majority of research participants believe that females will often say it first (Harrison \& Shortall, 2011, p. 728). But when asked who said "I love you" first in their partnerships, the majority said that the man in their relationship was the first to vocally say it (Harrison \& Shortall, 2011, p. 728). Personal experience does not outweigh people's belief in who says what in a romantic relationship. Although the majority of the participants had the same experience when expressing their love in their relationships, they still believed that they were the exception and that their experience was not a part of the majority, and they were convinced that their experience was unique.

A question that is present across most of the literature about the roles gender plays in expressing love in a romantic relationship is, 'Why do the stereotypes surrounding men and women in love still exist?' There has been a whole generation worth of time since the first studies were being conducted on this subject (Harrison \& Shorthall, 2011, p. 729). The world has been becoming more progressive, but people still play into the stereotypes. Why is it that when asked the question of 'who falls in love first?', both men and women will usually say women will say 'I love you' first, regardless of their own experience.

This notion of women being more romantic and falling in love more quickly may come from a multitude of sources. Whoever started portraying women as love hungry, emotional, whimsical beings, whose sole desire in life is to be in love, set a precedent that has remained present even in the twenty-first century. This idea that women fall madly in love and quickly does not come from actual research that has been done on love and romantic relationships. These ideas may be rooted by a lot of assumptions. There is potential that these stereotypes might be rooted by the idea that women are and become more emotionally invested in their relationships (DiDonato, 2016). Although women on average take longer to declare that they love their partner, once they reach the point of love and they feel that they are in a committed partnership, they then often express their love more freely and frequently (Ackerman et al., 2011, p. 1080).

In many movies and television shows, love and falling in love is in alignment with the general stereotype. We are constantly seeing on the screen a woman giving into her emotions and falling madly in love with a man who may or may not share the same feelings or even know she exists. We see the crazy women who stalk their man of interest, altering themselves in order to fit what they perceive the man wants. This way of portraying women demonstrates the idea that women are the ones who fall quickly in love, they give everything to their potential partner right away, and that they are the drivers of the love story. Examples of these characters can be seen in movies like "He's Just Not That Into You", where a number of the female characters fall head over heels for a guy before really getting the chance to actually know him. Also, in the movie "How To Lose A Guy In Ten Days", the best friend of the main character starts her debut in the movie as just having been broken up with because she moved too fast in the relationship. When she is asked why this might have happened, she innocently says all the very stereotypical and overtly 'in love' things she did, like tell him she loved him after a week, crying in front of him, and giving him her whole heart (Petrie, 2003, 07:05). These are popular movies that many people have seen, although they are fictional, the base of the characters resonates with the viewers. 
Being in love and expressing the sentiments that go along with it involve a certain amount of vulnerability. Vulnerability is often considered to not be an attribute that people want to have, but when it comes to love it is very important. Expressing ourselves is not something that comes easily to the majority of people. There is a general misgiving within society that men cannot be vulnerable and show weakness. Since vulnerability and love and the expression of love goes hand in hand, it is understandable that so many people do not believe that men are predominantly the first ones to say the locution, 'I love you'.

The misgivings of the stereotypes that perpetuate society are contradicted by the research done on love. But a reason for why these stereotypes still exist in people's minds could be attributed to the fact that later on in romantic relationships, once the partnership has become more solidified, women are more likely to express their love verbally and non-verbally more often (Harrison \& Shorthall, 2011). This could be a likely reason for why so many people believe that women fall in love and profess their love faster than men.

\section{Research}

A declaration of love is a bold statement. Saying "I love you" first takes courage, but it also takes vulnerability. Research has shown that in many cases, men say "I love you" first compared to women. The reason for this is not fully known. There are a broad range of reasons why this is the case. Research has shown that men tend to have a greater number of romantic tendencies than women, they feel passion and romance, which is very unlike the stereotype of the cold, emotionally unavailable man (Harrison \& Shorthall, 2011). This is a potential contributor to the fact that men fall in love faster than women and on average will say "I love you" first (Cruxes, Hawrylak \& Delegido, 2015, p. 90).

Understanding exactly why men say the three magical words first has not happened. There is a lot of speculation and believable theories, but no definitive answer has been given (Gareis \& Wilkins, 2006). There are a number of reasons why men have the tendency to express their love first, but a few that stand out are the way that men are socialized and how that influences all aspects of their life, including romantic partnership. A second idea is that because men have a greater belief in love at first sight, they are more ready to fall in love faster and with a varying range of partners than woman are (Rubin et al., 1981, p. 824). Another idea that is present is the notion that sex roles exists for each gender because of evolution and genetics and that their desire to mate and procreate influences their expressions of love.

The other side of the research is discovering why women are usually not the ones to say "I love you" first. This is just as important as the research that is done to determine why men are usually the first ones. The reasons for why women are more reserved and may not express their feelings of love nearly as soon as men can be attributed to a lot of reasons. Across much of the literature, researchers agree that women are not the ones to express themselves first in a romantic relationship and that they are a lot more calculated and cautious when it comes to showing their love initially (Harrison \& Shorthall, 2011, p. 734). A reason for why people might believe this is 
because later on in a relationship, once the initial "I love you's" have been exchanged, women are often more willing to express their emotions and feelings with their partners (Harrison \& Shorthall, 2011, p. 735).

\section{Contributing Factors for Gender Difference in Saying "I Love You” and Falling in Love}

The way people are, is largely affected by the way they were socialized. The socialization process, the way a person is taught and integrated into society, sets the ground work for how people behave in the future. Harrison and Shorthall (2011) say that a reason for why men say "I love you" first is because of the man's gender schema to be the one to solidify the romantic relationship ( $p$. 734). This goes both ways, for men and women. Another part that could play a role in these ideas is the societal expectations that are put on men and women, these expectations have a large impact on the way that people believe they should act, and in turn, influences their actions (Harrison \& Shorthall, 2011, p. 734).

In order for a person to get to the point of declaring out loud their love for a partner, a person needs to feel like they can disclose such intimate information. Ackerman, Griskevisius and Li (2011) see that this disclosure of such a personal thing by men can be attributed to the socialization pressures that exist that make men want to have a sense of control over the relationship, by being so forthcoming with their feelings they are setting the pace for the romantic partnership (p. 1080). Men are taught to that being dominant is a positive attribute. Men being dominant is different areas of life it is celebrated within society, so it is not far off to think that men may think that being the instigator in the love conversation is one more thing for them to be dominant at and thus be celebrated for.

Much like how men are affected by socialization, women are equally affected by it. Where men are told to be bold, powerful and strong, women are told to be soft, agreeable and passive. Although gender roles are being challenged and people are choosing to actively go against the traditional gender schemas when socializing their children, the traditional way of doing things still has a way of infiltrating the process. The conversation around love and the timeline of experiencing love may differ in the next twenty years, today it still looks a lot like it did decades ago. In the past, for females, finding a partner was extremely important. In the past, but to a lesser degree today, romantic partnership can have a huge impact on one's economic stability and their place in society. Because of the way that partnerships and relationships determined so many aspects of their lives, this could be a reason why women tend to be a bit more intentional and specific about their partner choice and be a bit more reserved when it comes to sharing their feelings (Rubin et al., 1981, p. 824).

Ellen Fein and Sherrie Schneider's book “The Rules: Time-tested Secrets for Capturing the Heart of Mr. Right" is a demonstration of how women have and continue to be socialized in society. The concept of "the rules" was not born with this book, rather, it is estimated that the rules started around the turn of the century and have prevailed all the way into contemporary society (Fein \& Schneider, 1995, p.1) This book was written in 1995 but says that the rules that are in the book are the same rules and advice that someone might hear from their grandmother (Fein \& Schneider, 1995, p. 1). They preface that the rules that are laid out in the book are the same rules 
that generation and generation of women have used and that they work. Some of the rules that they state are "Don't open up too fast", "Don't meet him halfway", and "Don't have sex too early" (Fein \& Schneider, 1995, p. 5). This book has sold hundreds of thousands of copies and has been the topic of conversation for many women. This book may seem archaic and very much not with the times, but the popularity of the book demonstrates that it is still very much a thing in today's modern world. The way that women and girls are socialized greatly impacts the way that they interact with the world throughout their lives. This book reinforces the ideas that women are supposed to be the object of a man's desire, a man is the one that chases the girl, and that a woman should not be too eager to spend time with a man or further the relationship. The funny part about this book is that it is directly opposite of the gender stereotypes that society believes to be true about women falling and being in love. Women are taught to be choosey when it comes to love and partnership, to not give too much away, and to not move too fast. This book is a real example as to explain why women are not the ones that instigate the "I love you" conversation.

Romance is a word that has different meanings for different people. Some people define romance as big grand gestures, others associate it with passionate words, while others see it as small thoughtful actions. In regard to men, who have greater romantic tendencies, does it mean that romance equates to love? This is a bold statement that may or may not be true. But since it is believed that men recognize and know their feelings of love before women, it could be said that romance and love do go hand-in-hand (Harrison \& Shorthall, 2011, p. 733). Ackerman et al. (2011) discovered through their research that not only do men say and feel love first, but that men actually feel that they love someone in only a few weeks where women often take a few months to discern their feelings (p. 1080).

The quickness of men realizing they are in love could also be attributed to their genetics and the evolution of their sex. This could also be said about women. Evolutionary theories believe that people have the innate desire to mate and procreate (Symons, 1979). With this information we know that men have the ability to have multiple partners and to have multiple offspring at the same time. Whereas with women, they can only have one pregnancy at a time, meaning that their chance of procreation is a lot lower and is much more time consuming. Men have the ability to be more cavalier and open to potential partnerships since they have more opportunity to procreate, whereas women need to be more diligent and calculated with their mate choice since they can only mate with one person at a time (Harrison \& Shorthall, 2011, p. 734). This is a factor to consider why women are more reserved when expressing their love for their partners and why females may have the tendency to focus on family in a stronger sense than males do (Asselmann \& Specht, 2020, p. 1805) This evolutionary theory translates into present day love and relationships not because everyone is consciously looking for a mating partner, but because the desire to procreate is hidden within a homosapien's genetic codes.

A not so romantic option for why men say "I love you" faster than women could be because of sex and the desire to have sexual relations with their partner. The statement 'I love you' has connotations of commitment written with in it. Since these three words are not casually thrown around, it can be thought that when people say it, they really mean it. This is an optimistic and wholesome thought, but it is not always the truth. Harrison and Shorthall (2011) hypothesize that if the male partner believes that their female partner thinks saying 'I love you' is romantic and solidifies the commitment needed to further their relationship, both emotionally and physically, 
then the man might just say it (p. 728). There is evidence that men put more emphasis on sex and are more interested in sex than women (Harrison \& Shorthall, 2011, p. 733). But it is important to note that there are definite differences between sexual desire and passionate love (Harrison \& Shorthall, 2011, p. 733). So, the link between men saying "I love you" first in order to have sexual relations cannot be concretely stated. But it is important to note that there is a chance that this could be an explanation for some portion of the male population.

\section{Cultural Differences}

It also needs to be pointed out that although love is a universal feeling, the way in which it is demonstrated and communicated is not culturally universal. Different cultures' expressions of love in intimate partnerships varies. For instance, in Finland, they use the expression of "I love you" less frequently than North Americans, saving it for special occasions and emotional moments (Wilkins \& Gareis, 2006). Wilkins and Gareis also say that love is a "delicate walk", full of ambiguity and grey areas, where sometimes love is felt but not verbally expressed, and other times it is only expressed verbally (2006). It is important to recognize that differences in regard to the expression of love and intimacy do not only exist between genders but also exist between cultures.

What is not considered in much of the research surrounding this phenomenon is the use of non-verbal expressions of love. Wilkins and Gareis (2006) discuss how the words "I love you" is thrown around in North America where everyone says it to everyone, whereas with a lot of other countries and cultures, those three words are saved for special moments and occasions. A lot of people do not take into considerations the actions that people do to express their love, but this is a very normal and popular way to share one's feelings. To some, continuously vocalizing their feelings of love can make the sentiment seem less genuine and diminishes the meaning that is trying to be expressed (Wilkins \& Gareis, 2006). When thinking about who says the locution of "I love you" first, the consideration for what has happened non-verbally prior to the moment is not really there.

\section{Conclusion}

Research on love and the expression of love has been going on for decades. To the surprise of a few, the results of the research has stayed relatively constant and the same. Love is a fascinating topic because it is felt by everyone in the world. Although there are different forms of love, when it comes to romantic love between two people (in this case a man and a woman), the stereotypes that exist within society do not hold up. The ongoing stereotype about romantic love is that it is pursued by women. Women are the ones that feel love first, they are the ones to express it first, and they fall harder. This notion and belief can be seen in so many facets of society, but it holds very little truth. People mix up the initial love that is felt in relationships to the way that these relationships look over time. The emphasis on stereotypes about love are often centered around women but it is important to recognize that men are also the victims of unfair and untrue stereotypes. Where women are thought to be overly emotional, men are thought to lack emotion. People believe that men are reserved and cold when it comes to love, that they are not in tune with 
their emotions and thus are not the ones to express their love first. This is refuted by research and has been refuted for decades. So why is it that these stereotypes still reign supreme in today's society? Why has the research not altered peoples initial thinking about the expression of love? These are hard questions to answer because the stereotypes are not actually rooted in any truth if people were to really think about it.

People are shaped by society. People act in specific ways because they are taught to or they believe that it is the proper way for them to act. Love is not exempt from societal beliefs. Societal expectations and norms have a huge influence on the manifestation of love. With studying the expression of love and its relation to genders, and specifically which gender professes their love first, a lot of the answers lie within the socialization process. Even as the world becomes more egalitarian and equal, gender differences still exist. Men are taught to be powerful and to have control, and women are taught to be agreeable and expressive. These taught tendencies affect so many aspects of their lives and it is only fair to say that they also affect a person's love life. A contributing factor as to the reasons why men and women are socialized differently can be linked to our evolution as a human species. As a species it is our duty to procreate and with procreation there is certain limitations that are put on both sexes.

The reasons for why men fall in love and say "I love you" first has no clear-cut answer. There are a lot of factors that have the potential to influence this aspect of their lives. The same goes for women, there is no definitive answer for why women do not recognize they are in love until much later than men and why they are usually not the first ones to say the three magical words. What is important about the research that has been done focusing on love expression is that the stereotypes that exist are inexplicably wrong. Women do not fall in love faster than men and men do have the ability to express their love to their partners and they often do it quickly. Women take time to pick a partner, they are level headed and thoughtful when deciding who they want to love. Men are not always calculated and cold, they have the ability to feel their emotions quickly and to experience the vulnerability that is involved in order to express one's feelings of love.

Love is a wonderful emotion. It is a worldwide phenomenon that has the ability to connect people in ways that nothing else can. Love is beautiful and love is surprising. "I love you" is a statement that has the ability to alter people's lives for the better. Experiencing being loved and being in love is a profound gift that hopefully everyone is fortunate enough to experience. 


\section{References}

Ackerman, J.M., Griskevicius, V. \& Li, N.P. (2011). Let's get serious: Communicating commitment in romantic relationships. American Psychological Association, 100(6), 1079-1094. DOI: 10.1037/a0022412

Asselmann, E. \& Specht, J. (2020). Taking the ups and downs at the rollercoaster of love: Associations between major life events in the domain of romantic relationships and the big five personality traits. American Psychological Associations, 56(9), 1803-1816. DOI: http://dx.doi.org/10.1037/dev0001047

Cruces, J.M., Hawrylak, M.F. \& Delegido, A.B. (2015). Interpersonal variability of the experience of falling in love. International Journal of Psychology and Psychological Theory, 15(1), 87-100.

http://content.ebscohost.com/ContentServer.asp?EbscoContent=dGJyMNLr40Sep7U4zO X0OLCmsEiep7NSsq\%2B4TbeWxWXS\&ContentCustomer=dGJyMPGqt0uyrLVRuePf geyx43zx 1\%2B6B\&T=P\&P=AN\&S=L\&D=a9h\&K=102555960

DiDonato, T.E. (2016, Mar 24). Who says “I love you” first (and why)? Psychology Today. https://www.psychologytoday.com/us/blog/meet-catch-and-keep/201603/who-says-ilove-you-first-and-why

Fein, E. \& Schneider, S. (1995). The Rules: Time-tested secrets for capturing the heart of Mr. Right. New York, NY. Grand Central Publishing.

Gareis, E. \& Wilkins, R. (2006). Emotion expression and the locution "I love you": A crosscultural study. International Journal of Intercultural Relations. 30(1), 51-75. DOI: https://doi.org/10.1016/j.ijintrel.2005.07.003

Harrison, M.A. \& Shortall, J.C. (2011). Women and men in love: Who really feels it and says it first? The Journal of Social Psychology, 151(6), 727-736. Doi:

Petrie, D. (2003). How to lose a guy in 10 days. Paramount Pictures.

Rubin, Z., Peplau, L.A. \& Hill, C.T. (1981). Loving and leaving: Sex differences in romantic attachments. Sex Roles, 7(8), 821-835.

http://content.ebscohost.com/ContentServer.asp?EbscoContent=dGJyMNLr40Sep7U4zO X0OLCmsEieqLFSs6a4SLaWxWXS\&ContentCustomer=dGJyMPGqt0uyrLVRuePfgey $\underline{x} 43 \mathrm{zx} 1 \% 2 \mathrm{~B} 6 \mathrm{~B} \& \mathrm{~T}=\mathrm{P} \& \mathrm{P}=\mathrm{AN} \& \mathrm{~S}=\mathrm{R} \& \mathrm{D}=\mathrm{sih} \& \mathrm{~K}=24403020$

Symons, D. (1979). The evolution of human sexuality. New York, NY: Oxford University Press. 